\title{
Optimization of Milling Parameters of Aluminium Alloy 7075 for Face Milling Using Finite Element Method
}

\author{
Harshal Ratnakar Ghan \\ Research Scholar \\ Mechanical Engineering \\ Oriental University, Indore \\ harshal_ghan@yahoo.com
}

\author{
Dr.Prof. Netra Pal Singh \\ Professor \\ Mechanical Engineering \\ Oriental University, Indore
}

\begin{abstract}
The effect of Spindle Speed, Feed rate, and Depth of cut on the Surface Roughness of Al-7075 alloy during face milling is the subject of this study [1]. To examine the machining attributes of $\mathrm{Al-7075}$ amalgam, eight exploratory runs dependent on a L9 symmetrical cluster of Finite Element strategy are utilized. [2]. the optimization of processing parameters improves not only the processing economy, but in addition the item quality to a huge degree. The $\mathbf{7 0 0 0}$ series aluminium alloy Al 7075 can be used in a large number of applications [3]. The thinness and hardness of grade 7075 are highly valued by both manufacturers and end users. With the use of experimental design techniques, this article analyses and compares the contribution of cutting parameters, such as MMR and MT, to quality characteristics [4]. Using Explicit Dynamics Analysis, the authors present a FEM model for face milling of AISI 7075. This model will simulate the formation of chips during the process. The consequences of dynamic motion, the constitutive harm law, and touch friction are all considered. [5].
\end{abstract}

Keywords: Aluminium 7075 alloys; CNC; machining time; Finite Element Method; Material Removal Rate (MRR); surface roughness

\section{INTRODUCTION}

Aluminium alloys are widely used as a primary engineering material in a variety of industries, including aerospace, mould and die part manufacturing, and industries where weight is a critical factor. These products are easy to machine and have a high machinability index [6]. Milling is quite possibly the most significant and inescapable metal cutting activities utilized for machining parts in todays highly automated and computer integrated manufacturing world because of its capacity to strip materials quicker while maintaining a reasonable Surface quality [7].

\section{A. Milling}

Milling is quite possibly the most generally utilized machining measures in aluminum alloy forming. Milling is a central machining measure which is utilized to create level and complex shapes with the utilization of multi - point cutting instrument which is called processing shaper and the forefronts are called teeth [8].

\section{B. $\mathrm{CNC}$}

Computer Numerical Control (CNC) is a material expulsion measure used for the fabrication parts with convoluted size and shapes just as profiles. CNC processing is most typically utilized in enterprise and computing device appears for machining components to specific sizes and shapes with prefer floor great and greater effectivity interior much less time and cost [9].

\section{Face Milling}

Face milling is extremely basic technique for completing of new materials and machined materials. In face milling, the shaper is delivered on a shaft. The hub of flip of shaper is contrary to the workpiece surface. The distance throughout of shaper both equal to width of workpiece and greater distinguished than width of workpiece which ought to be machined [10].

The fundamental goal of the examination work is to discover the ideal qualities for the chose control factors to diminish machining time (MT) utilizing Taguchi's strong plan strategy and to build up the expectation models for machining time considering the control factors [11]. In the current work Finite Element Method is used to choose the ideal cutting milling parameters are all the more productively and the three cutting boundary are Shaft Speed, Feed rate and Depth of cut are utilized in three diverse level in the venture work. The Al-7075 based metal grid composite is utilized as the work piece. Finite Element method is utilized to enhance the cycle boundary for example surface roughness and MRR utilizing sign to commotion proportion for milling cycle of the work piece materials [12].

\section{MATERIALS}

\section{A. Cutting tool material}

Face milling, which incorporates material choice and calculation, is quite possibly the principal elements that have an effect on floor roughness and the mechanical properties. Instrument materials, apart from having to acceptably persevere thru the processing activity, affect floor roughness and gadget wear. With regards to machining, a reducing equipment is any instrument that is utilized to remove cloth from the workpiece via shear deformation. Cutting apparatuses ought to be made of a cloth more difficult than the fabric which is to be cut, and the instrument ought to have the alternative to face up to the heat created in the metal-cutting interaction. Likewise, the instrument must have a precise math, with freedom factors deliberate so the bleeding facet can contact the workpiece barring the rest of the gadget delaying the workpiece surface [13].

Therefore, the cutting tool material is selected as follows:

1. Tungsten 


\section{B. Workpiece material}

In this present work Al-7075 based Metal Matrix Composites (MMCs) material is used.

\section{Methodology}

\section{A. Machining characteristics}

The most essential machining characteristics regarded in the current work are:

\section{1) Surface Roughness $\left(R_{a}\right)$ :}

Surface finish is a crucial factor in deciding a product's surface quality. The quintessential absolute cost of the height of the roughness profile over the contrast length (L) is the average Surface Roughness, which is expressed by the equation below. Where ' $L$ ' denotes the duration of the formula,

$$
\mathrm{R}_{\mathrm{a}}=\frac{1}{\mathrm{~L}} \int_{0}^{\mathrm{L}}|\mathrm{Y}(\mathrm{x}) \mathrm{dx}|
$$

Perception and ' $Y$ ' is the ordinate of the profile bend. Surface Roughness Analyzer (Stylus test type Profilometer) is utilizations to evaluate surface cruelty of work piece in microns $(\mu \mathrm{m})$. [14]

\section{2) Material Removal Rate (MRR):}

The amount of material extracted from the work piece surface per unit time is known as the Material Removal Rate. The amount of material removed divided by the time it took to cut can be used to measure material removal rate. The initial volume of the work piece is subtracted from the final volume to get the volume removed. The Cutting time is the time required for the gadget to journey via the size of the work piece. This boundary unequivocally impacts the completing evaluation of the work piece [15].

$$
\operatorname{MRR}=\left[\left(\mathrm{W}_{\mathrm{b}}-\mathrm{W}_{\mathrm{a}}\right) /(\mathrm{T} \times \mathrm{Q})\right] \times 1000
$$

Where,

$\mathrm{W}_{\mathrm{b}}=$ Weight of the workpiece before machining (grams).

$\mathrm{W}_{\mathrm{a}}=$ Weight of the workpiece after machining (grams).

$\mathrm{T}=$ Machining time period (minutes).

$\mathrm{Q}=$ Density of work piece material $(\mathrm{grams} / \mathrm{cm} 3$

\section{3) Machining Time (min.):}

$$
\text { Machining time }=\mathrm{L} / \mathrm{f}_{\mathrm{N}}
$$

Where,

$$
\mathrm{L}=\text { Length of tool travel }(\mathrm{mm})
$$$$
\mathrm{f}_{\mathrm{N}}=\text { Feed velocity }(\mathrm{mm} / \mathrm{min})
$$

\section{B. Explicit Dynamics Analysis:}

ANSYS Explicit Dynamics is a transient explicit dynamics Workbench programme that can be used to perform a wide range of engineering simulations, including modelling of nonlinear dynamic behavior of solids, fluids, gases, and their interactions. The Workbench LS-DYNA extension can also be used to test a model with the LS-DYNA solver. Setting up the model, interactions, and utilized loads, fixing the model's nonlinear dynamic response over time for the masses and interactions, and examining the specifics of the response the use of a vary of on hand techniques are all phase of a well known simulation [16].
The Explicit Dynamics application has objects engineered in a tree structure that oversee you through the different steps of a reenactment. By expanding the things, you uncover the unpretentious ties related with the article, and you can use the contrasting instruments and detail tables with play out that piece of the diversion. Articles are used, for example, to portray biological conditions, for instance, contact surfaces and loadings, and to describe the sorts of results you need to have available for overview [17].

The partial differential equations to be addressed in an Explicit Dynamics investigation categorical the safety of mass, force, and electricity in Lagrangian facilitates. These, alongside with a fabric mannequin and a bunch of introductory and restriction conditions, characterize the complete association of the problem. For the Lagrangian plans at current on hand in the Explicit Dynamics framework, the go area strikes and contorts with the fabric it indicates and protection of mass is for this reason fulfilled [18]. The density each time can be resolved from the present day extent of the area and its preliminary mass

$$
\frac{\rho_{0} \mathrm{~V}_{0}}{\mathrm{~V}}=\frac{\mathrm{m}}{\mathrm{V}}
$$

The partial differential equations that express the conservation of momentum relate the acceleration to the stress tensor $\sigma_{\mathrm{ij}}$.

$$
\begin{array}{r}
\rho \ddot{\mathrm{X}}=\mathrm{b}_{\mathrm{X}}+\frac{\delta \sigma_{\mathrm{xx}}}{\delta \mathrm{x}}+\frac{\delta \sigma_{\mathrm{xy}}}{\delta \mathrm{y}}+\frac{\delta \sigma_{\mathrm{xz}}}{\delta \mathrm{z}} \\
\rho \ddot{\mathrm{Y}}=\mathrm{b}_{\mathrm{y}}+\frac{\delta \sigma_{\mathrm{yx}}}{\delta \mathrm{x}}+\frac{\delta \sigma_{\mathrm{yy}}}{\delta \mathrm{y}}+\frac{\delta \sigma_{\mathrm{yz}}}{\delta \mathrm{z}} \\
\rho \ddot{\mathrm{Z}}=\mathrm{b}_{\mathrm{z}}+\frac{\delta \sigma_{\mathrm{zx}}}{\delta \mathrm{x}}+\frac{\delta \sigma_{\mathrm{zy}}}{\delta \mathrm{y}}+\frac{\delta \sigma_{\mathrm{zz}}}{\delta \mathrm{z}}
\end{array}
$$

These conditions are addressed expressly for every component in the model, in light of info esteems toward the finish of the past time step. Modest additions are utilized to guarantee steadiness and exactness of the arrangement.

\section{Explicit Time Integration:}

The Explicit Dynamic solver uses a central difference time integration scheme

Therefore the accelerations are;

$$
\ddot{X}_{i}=\frac{F_{i}}{m}+b_{i}
$$

Where;

$\mathrm{X}_{\mathrm{i}}$ - The components of nodal acceleration $(\mathrm{i}=1,2,3)$

$F_{i}$ - The forces acting on the nodal points

$b_{i}$ - The components of body acceleration

$\mathrm{m}$ - The mass attributed to the node.

\section{Tool Used}

\section{1) Ansys 19.2:}

. Ansys Mechanical is a full-featured FEA (finite element analysis) instrument for structural analysis, including linear, nonlinear, and dynamic tests. The designing recreation item gives a total arrangement of components conduct, material models and condition solvers for a wide scope of mechanical plan issues. Moreover, ANSYS Mechanical offers warm examination and coupled-physical science capacities includ- 
ing acoustic, piezoelectric, warm underlying and thermoelectric investigation.

ANSYS structural analysis software, built on a firm base of element and material science, provides a variety of sophisticated simulation approaches for a variety of applications.

\section{2) SOLID185 Element:}

. SOLID185 is a programme for modelling solid structures in 3- dimensions. It is made up of eight nodes, each of which has three degrees of freedom: interpretations in the nodal $\mathrm{X}, \mathrm{Y}$, and $\mathrm{Z}$ directions. The component is versatility, hyper flexibility, stress solidifying, creep, huge diversion, and huge strain abilities. It additionally has blended detailing capacity for reenacting misshapenness of almost incompressible elastoplastic materials, and completely incompressible hyperplastic materials.SOLID185 is available in two forms:

- Homogeneous Structural Solid.

- $\quad$ Layered Structural Solid (Used in this study)

\section{RESULTS}

\section{A. Results}

1) The dimensions was taken for the analysis are as follow.

TABLE I. DIMENSIONS OF WORKPIECE AND CUTTING TOOL

\begin{tabular}{rrrccc}
\hline Sr. & \multirow{2}{*}{ Type } & Material & \multicolumn{3}{c}{ Dimensions (mm) } \\
\cline { 4 - 6 } No. & & & Length & Width & Height \\
\hline 1. & Workpiece & AL 7075 & 100 & 40 & 40 \\
2. & Cutting tool & Tungsten & 60 & 50 & 30 \\
\hline
\end{tabular}

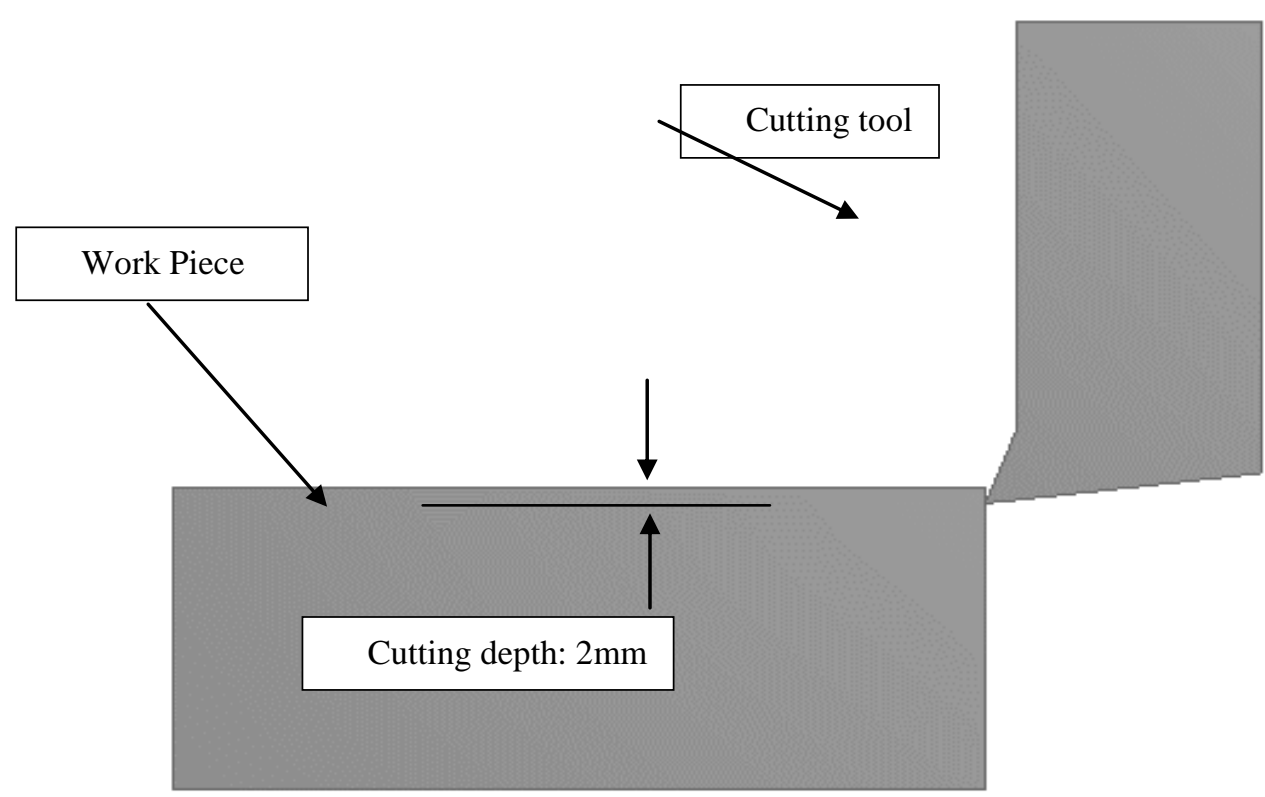

Fig. 1. CAD modelling of model

2) Material properties

a) Tungsten material properties

TABLE II. TUNGSTEN MATERIAL PROPERTIES

\begin{tabular}{ccc}
\hline Sr. No. & Property & Value \\
\hline 1. & Density & $2804 \mathrm{~kg} / \mathrm{m}^{3}$ \\
2. & Specific heat, $\mathrm{C}_{\mathrm{p}}$ & $848 \mathrm{~J} / \mathrm{kg}^{\circ} \mathrm{C}$ \\
3. & Initial Yield Stress Y & $420 \mathrm{MPa}$ \\
4. & Max. Yield Stress Y ${ }_{\max }$ & $810 \mathrm{MPa}$ \\
5. & $\mathrm{dG} / \mathrm{dP}$ G'P & 1.741 \\
6. & $\mathrm{dG} / \mathrm{dT}$ G'T & $-1.645+07 \mathrm{~Pa}{ }^{\circ} \mathrm{C}$ \\
7. & $\mathrm{dY} / \mathrm{dT} \mathrm{Y}^{\prime} \mathrm{P}$ & 0.02738 \\
8. & Shear Modulus & $2.67 \mathrm{E}+11 \mathrm{~Pa}$ \\
9. & Parameter Quadratic & $0 \mathrm{~s} / \mathrm{m}$ \\
\hline
\end{tabular}




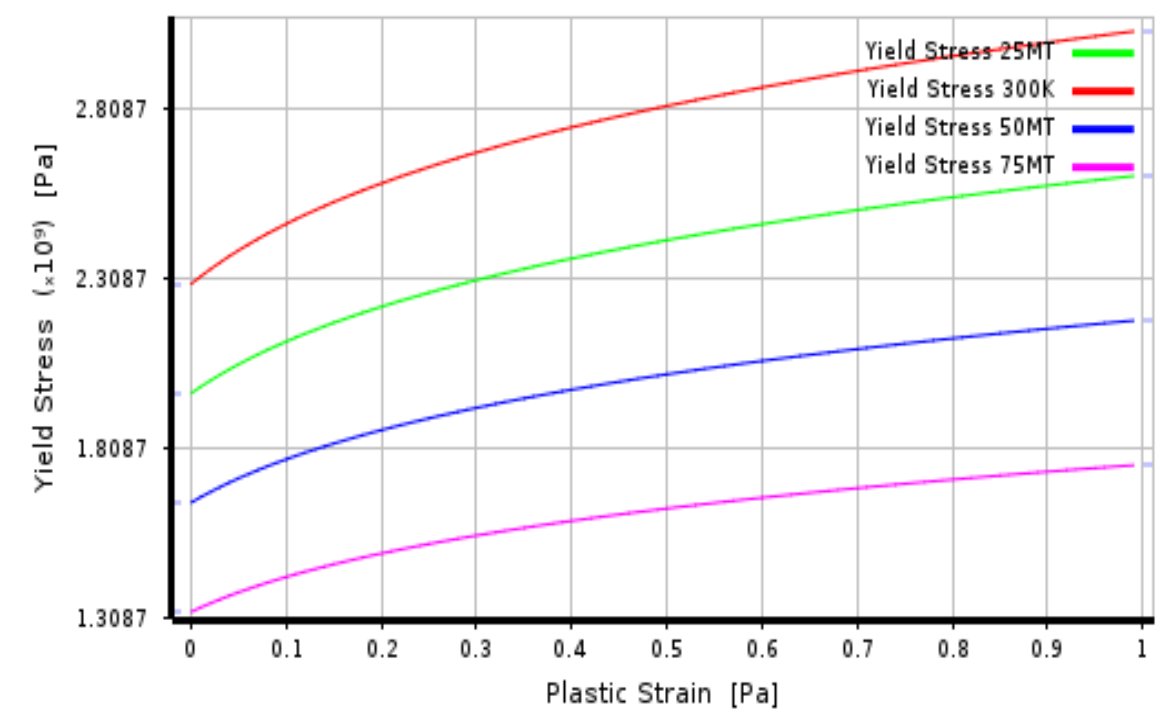

Fig. 2. Tungsten Material Properties- Yield Stress

TABLE III. YIELD STRESS VALUES AT DIFFERENT PLASTIC STRAIN VALUES FOR TUNGSTEN MATERIAL

\begin{tabular}{ccccc}
\hline \multirow{2}{*}{$\begin{array}{c}\text { Plastic Strain } \\
(\mathrm{Pa})\end{array}$} & \multicolumn{4}{c}{ Yield Stress $\left(\mathrm{x} \mathrm{10}{ }^{8}\right)[\mathrm{Pa}]$} \\
\cline { 2 - 4 } & $300 \mathrm{~K}$ & $25 \mathrm{MT}$ & $50 \mathrm{MT}$ & $75 \mathrm{MT}$ \\
\hline 0 & 2.30 & 1.95 & 1.63 & 1.32 \\
0.1 & 2.49 & 2.07 & 1.75 & 1.39 \\
0.2 & 2.6 & 2.2 & 1.84 & 1.45 \\
0.3 & 2.69 & 2.3 & 1.91 & 1.50 \\
0.4 & 2.76 & 2.39 & 1.95 & 1.55 \\
0.5 & 2.82 & 2.43 & 2.01 & 1.59 \\
0.6 & 2.88 & 2.48 & 2.05 & 1.63 \\
0.7 & 2.95 & 2.52 & 2.1 & 1.67 \\
0.8 & 3.01 & 2.55 & 2.14 & 1.70 \\
0.9 & 3.06 & 2.58 & 2.17 & 1.73 \\
1 & 3.11 & 2.62 & 2.2 & 1.75 \\
\hline
\end{tabular}

b) AL 7075 Material properties

TABLE IV. AL 7075 MATERIAL PROPERTIES

\begin{tabular}{ccc}
\hline Sr. No. & Property & Value \\
\hline 1. & Density & $19300 \mathrm{~kg} / \mathrm{m}^{3}$ \\
2. & Specific heat, Cp & $129 \mathrm{~J} / \mathrm{kg}^{\circ} \mathrm{C}$ \\
3. & Initial Yield Stress Y & $2200 \mathrm{MPa}$ \\
4. & Max. Yield Stress Ymax & $4 \mathrm{E}+09 \mathrm{~Pa}$ \\
5. & Hardening Constant B & 7.7 \\
6. & Hardening Exponent & 0.13 \\
7. & dG/dP G'P & 1.501 \\
8. & dG/dT G'T & $-2.028 \mathrm{E}+07 \mathrm{~Pa} /{ }^{\circ} \mathrm{C}$ \\
9. & dY/dT Y'P & 0.02064 \\
10. & Shear Modulus & $1.6 \mathrm{E}+11 \mathrm{~Pa}$ \\
11. & Parameter Quadratic & $0 \mathrm{~s} / \mathrm{m}$ \\
\hline
\end{tabular}




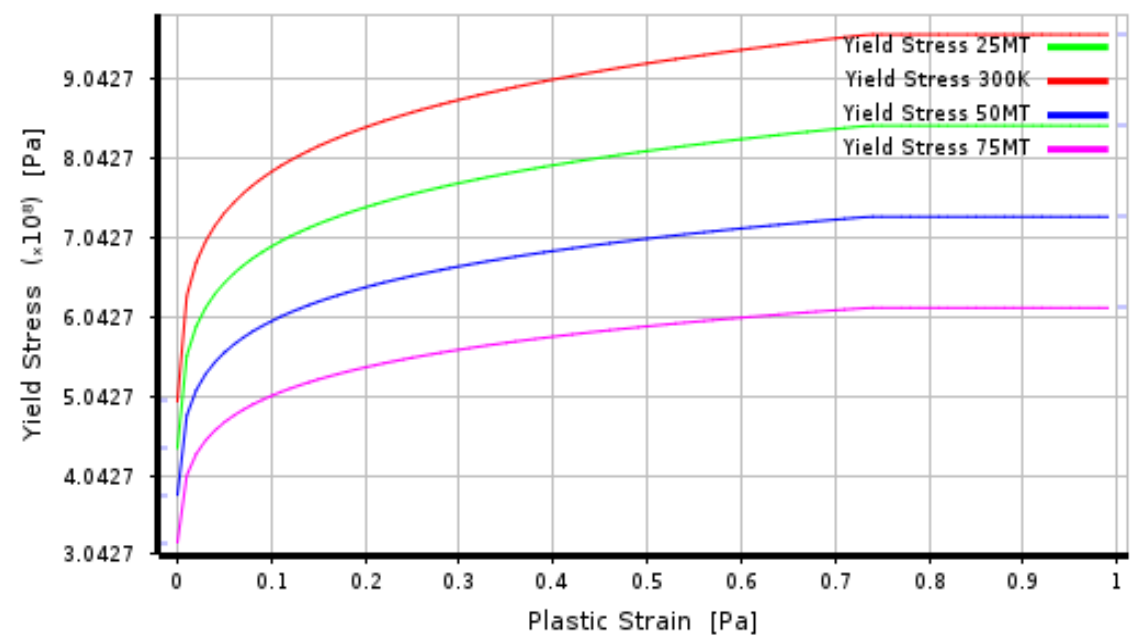

Fig. 3. AL 7075 Material Properties - Yield Stress

TABLE V. YIELD STRESS VALUES AT DIFFERENT PLASTIC STRAIN VALUES FOR TUNGSTEN MATERIAL

\begin{tabular}{ccccc}
\hline $\begin{array}{c}\text { Plastic Strain } \\
(\mathrm{Pa})\end{array}$ & \multicolumn{4}{c}{ Yield Stress $\left(\mathrm{x} \mathrm{10} 0^{8}\right)[\mathrm{Pa}]$} \\
\cline { 2 - 5 } & $300 \mathrm{~K}$ & $25 \mathrm{MT}$ & $50 \mathrm{MT}$ & $75 \mathrm{MT}$ \\
\hline 0 & 4.85 & 4.35 & 3.75 & 3.25 \\
0.1 & 7.80 & 6.87 & 5.94 & 5.09 \\
0.2 & 8.35 & 7.41 & 6.45 & 5.37 \\
0.3 & 8.75 & 7.72 & 6.67 & 5.6 \\
0.4 & 9.04 & 7.87 & 6.77 & 5.7 \\
0.5 & 9.16 & 8.14 & 7.04 & 5.85 \\
0.6 & 9.32 & 8.23 & 7.13 & 6.04 \\
0.7 & 9.46 & 8.31 & 7.27 & 6.1 \\
0.8 & 9.54 & 8.35 & 7.25 & 6.15 \\
0.9 & 9.54 & 8.35 & 7.25 & 6.15 \\
1 & 9.54 & 8.35 & 7.25 & 6.15 \\
\hline
\end{tabular}

3) FEA Results:

a) Machining Morphology:

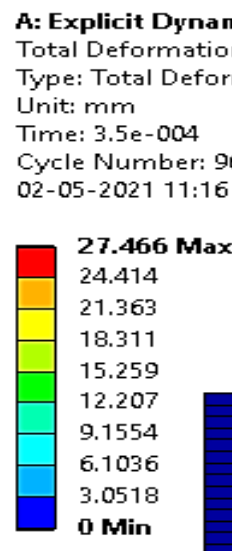

TotalDeformation 2

Type: Total Deformation

Unit: $\mathrm{mm}$

Cycle Number: 9600

$02-05-202111: 16$

Fig. 4. Deformation of machining 


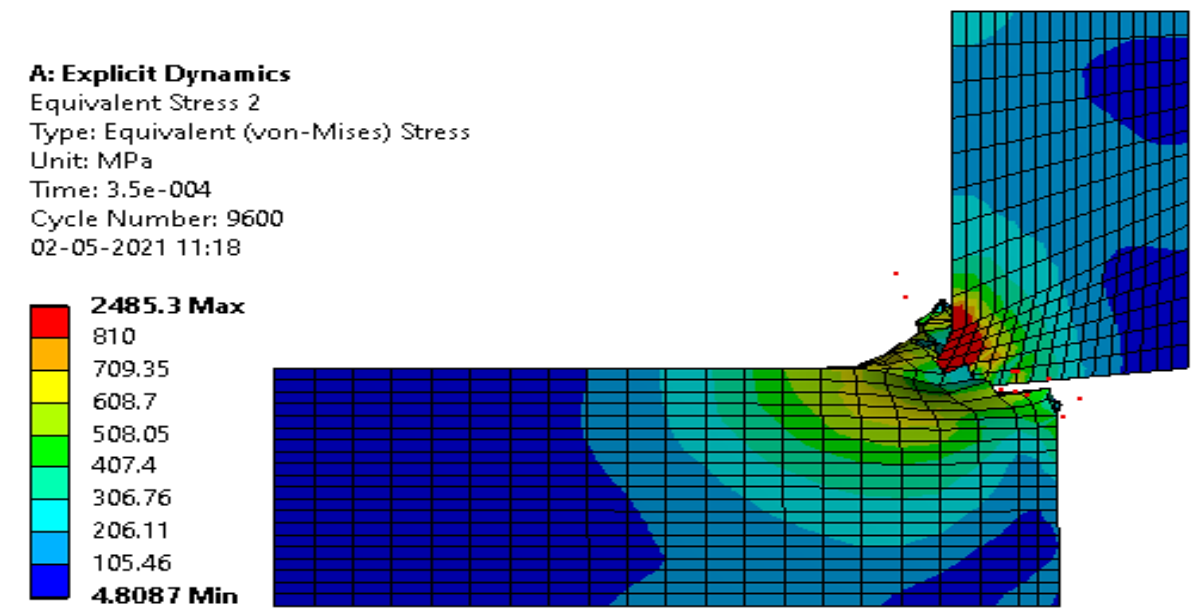

Fig. 5. Von Misses Stress Plot

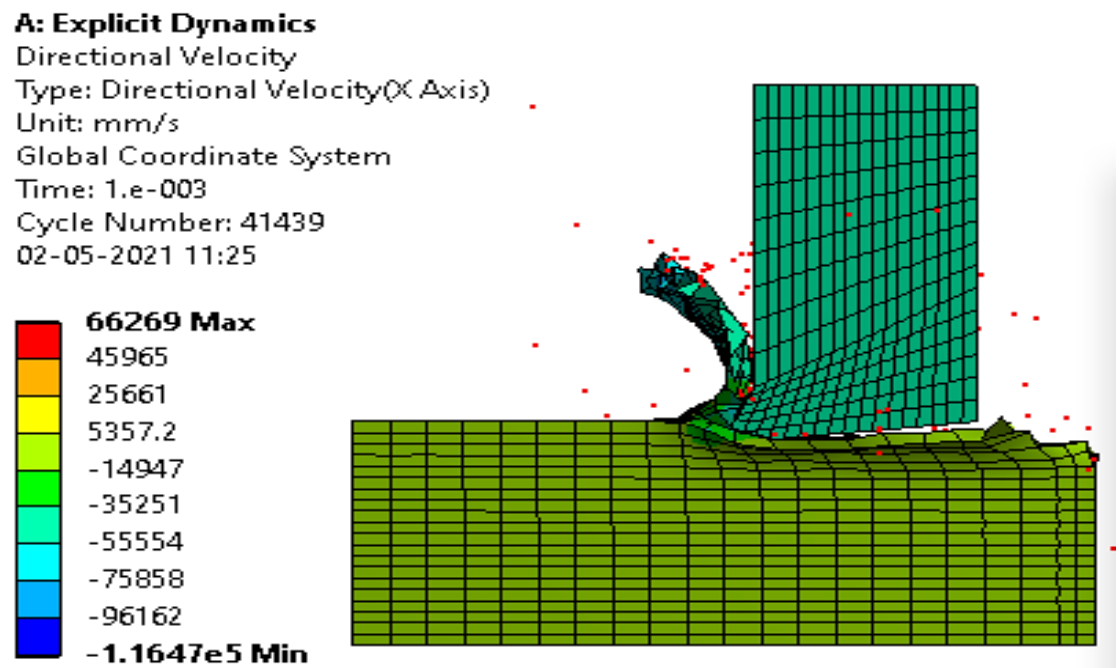

Fig. 6. Output velocity acting while machining

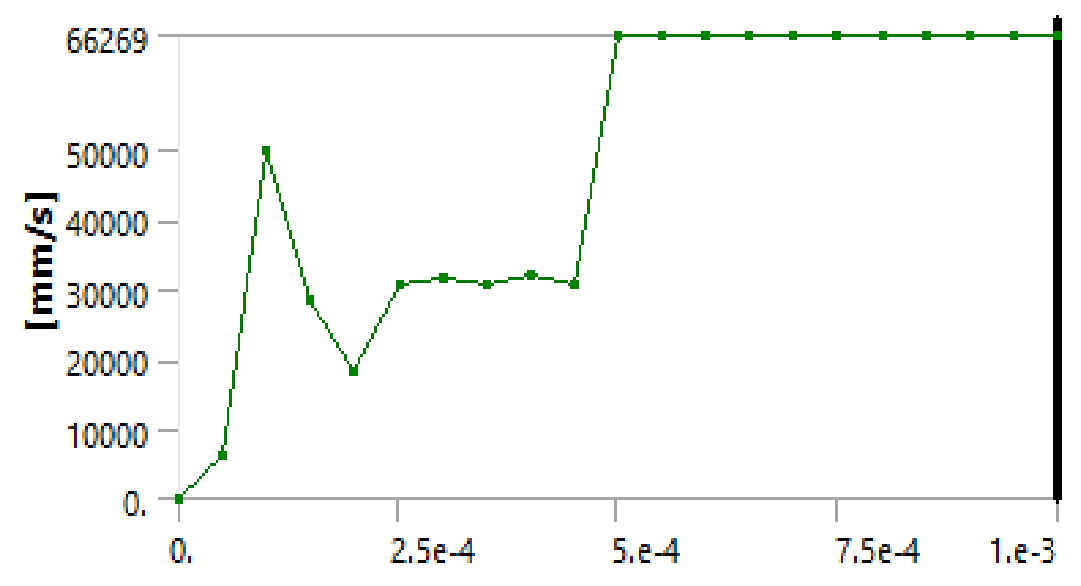

[s]

Fig. 7. Output velocity acting while machining

\section{CONCLUSION}

In this study, Machining process, which is mainly used for machining of metals, casting etc, has been analyzed by Finite Element Method. A simplified and idealized finite element model has been used in the analyses.
Following conclusion also made from this research work:

1. We have provided a full method for simulating the cutting process in this paper. 
2. The machining simulation shows the significance of using a material loss model to generate new free surfaces.

3. For manufacturing uses, the simulation tool proved to be very scalable and cost-effective. The effects of cutting process parameters are clearly visible, allowing you to choose the right process settings.

4. From Table No. $5 \mathrm{t}$ is observed that the Yield Stress of $\mathrm{Al} 7075$ is constant from $0.8 \mathrm{~Pa}$ plastic strain, so that it is concluded that $\mathrm{Al} 7075$ under constant stress with varying plastic strain.

5. It is also observed that Yield stress line at $300 \mathrm{~K}$ is rapidly increases as compared with other stress line.

\section{REFERENCES}

[1] R. N. Nimase et. al.," Effect of Machining Parameters on Surface Roughness of Al-7075 Alloy in End Milling", International Research Journal of Engineering and Technology (IRJET) e-ISSN: 2395 -0056 Volume: 02 Issue: 03 | June-2015 www.irjet.net p-ISSN: 2395-0072.

[2] Ashok Jain et. al., "A Review on Finite Element Method for Machining of Composite Materials", International Journal of Engineering Research and Technology, ISSN:2278-0181, vol. 7, Issue 11, November-2018.

[3] J. A. Ghani, I.A. Choudhary, H. H. Hassan, "Application of Taguchi method in the optimization of end milling parameters", ELSEVIER,JMPT, Vol. 145, pp. 84-92. 2004.

[4] S. Kumar, A. K. Guta, P. Chandna "State Of Art Optimization Techniques For Machining Parameters Optimizations During Milling" IJEAT, ISSN: 2249 - 8958, Volume-8 Issue-6, August 2019.

[5] Hamed Sadeghinia et. al., "2D finite element modeling of face milling with damage effects", 3rd WSEAS International Conference on APPLIED and THEORETICAL MECHANICS, Spain, December 14$16,2007$.

[6] K. Kadirgama, M. M. Noor, N. M. Zuki. N.M, M. M. Rahman, M. R. M. Rejab, R. Daud, K. A. Abou-El-Hossein, "Optimization of surface roughness in end milling on mould aluminium alloys (AA6061-T6) using response surface method and radian basis function network", Jordan Journal of Mechanical and Industrial Engineering, Vol. 2, 2008, 209- 214.

[7] Dukhit Kumar Chandel et. al.," A REVIEW ON OPTIMIZATION OF CUTTING PARAMETERS IN MACHINING USING TAGUCHI
METHOD”, International Research Journal of Engineering and Technology (IRJET) e-ISSN: 2395-0056 Volume: 06 Issue: 07 | July 2019 www.irjet.net p-ISSN: 2395-0072

[8] P. A. Suta ${ }^{\mathrm{r} 1}$, Prof. (Dr.) A. J. Guja "A Review On Effect Of Machining Parameters For End Milling Operation" JETIR, ISSN2349-5162, May 2017, Vol. 4, Iss.05, 2017.

[9] Mayur N. et. al.," Optimization of CNC Face Milling Process Parameters for Inconel 718 by Using Taguchi Method - A Review", International Research Journal of Engineering and Technology (IRJET) e-ISSN: 2395 -0056 Volume: 04 Issue: 04 |Apr -2017 www.irjet.net p-ISSN: 2395-0072.

[10] M. Alauddin, M.A. E1 Baradie and M.S.J. Hashmi, Optimization of surface finish in end milling Inconel 718, Journal of Materials Processing Technology, 56, 1996,54-

[11] Lohithaksha M Maiyar et. al.," Optimization of Machining Parameters for End Milling of Inconel 718 Super Alloy Using Taguchi Based Grey Relational Analysis", International Conference on DESIGN AND MANUFACTURING, IConDM 2013.

[12] Ankit kumar saxena et. al.," OPTIMIZATION OF MACHINING PARAMETERS FOR TURNING OF ALUMINIUM ALLOY LM4 USING TAGUCHI METHOD", International Research Journal of Engineering and Technology (IRJET) e-ISSN: 2395-0056 Volume: 05 Issue: 04 | Apr-2018 www.irjet.net p-ISSN: 2395-0072.

[13] W. Li, Y.B. Guo, M.E. Barkey, J.B. Jordon, Effect tool wear during end milling on the surface integrity and fatigue life of Inconel 718, 6thCIRPInternational Conference on High Performance Cutting,14, 2014, $546-551$.

[14] Avinash A. Thakre, "Optimization of Milling Parameters for Minimizing Surface Roughness Using Taguchi's Approach", International Journal of Emerging Technology and Advanced Engineering, Volume 3, Issue 6, June 2013, pp. 226-230.

[15] Mihir Thakorbhai Patel, "Optimization of Milling Process Parameters A Review-International Journal of Advanced Research in Engineering and Applied Sciences, Vol. 4, No. 9, September 2015.

[16] Mukhopadhyay CK, Jayakumar T, Raj B, Venugopal S, “ Statistical analysis of acoustic emission signals generated during turning of a metal matrix composite", J Braz Soc Mech Sci Eng 34:145-154, (2012).

[17] Shetty N, Shahabaz SM, Sharma SS, Shetty SD, "A review on finite element method for machining of composite materials." Compos Struct 176:790-802. https://doi.org/10.1016/j.compstruct.2017.06.012.

[18] M. Ugrčić, Application of the hydrodynamic theory and the finite element method in the analysis of bird strike in a flat barrier. Sci. Tech. Rev. 62(3-4), 28-37 (2012) 